\title{
TAXA DE RECORRIBILIDADE, TAXA DE REVERSIBILIDADE E EFICIÊNCIA JUDICIAL
}

\author{
APPEAL RATE, REVERSAL RATE AND JUDICIAL EFFICIENCY \\ TASA DE RECORRIBIDAD, TASA DE REVERSIBILIDAD Y EFICIENCIA JUDICIAL
}

IVO TEIXEIRA GICO JUNIOR

https://orcid.org/0000-0003-4831-3260 / http://lattes.cnpq.br/4070906323347938 / gico@ghdadvogados.com.br Centro Universitário de Brasília - UniCeuB.

Brasília, Distrito Federal

HenRIQUe HARUKI ARAKE

https://orcid.org/0000-0003-0552-8958 / http://lattes.cnpq.br/8829187912291856 / arake@ghdadvogados.com.br

Centro Universitário de Brasília - UniCeuB.

Brasília, Distrito Federal

\begin{abstract}
RESUMO
O presente artigo explora como um estudo da taxa de recorribilidade e da taxa de reversibilidade de um determinado órgão jurisdicional pode revelar a dinâmica processual em qualquer jurisdição e apontar soluções para melhorar a prestação do serviço público adjudicatório. Após uma contextualização da lógica juseconômica do litigio, apresenta-se a metodologia de estimativa das referidas taxas e realiza-se um experimento exploratório com alguns casos do TJDFT.
\end{abstract}

Palavras-chave: Judiciário, Eficiência, Taxa de Recorribilidade, Taxa de Reversibilidade.

\section{ABSTRACT}

The present paper explores how a study of the appealability rate and the reversal rate of a given court can reveal the procedural dynamics in any jurisdiction and point out solutions to improve the performance of the public adjudicative service. After discussing the law \& economics logic of litigation, the methodology for estimating the referred rates is presented and an exploratory experiment is carried out with some cases of the TJDFT.

Keywords: Judiciary, Efficiency, Appeal Rate, Reversal Rate

\section{RESUMEN}

El presente artículo explora cómo un estudio de la tasa de recaudación y de la tasa de reversibilidad de un determinado órgano jurisdiccional puede revelar la dinámica procesal en cualquier jurisdicción y señalar soluciones para mejorar la prestación del servicio público adjudicatorio. Después de una contextualización de la lógica justificativa del litigio, se presenta la metodología de estimación de las referidas tasas y se realiza un experimento exploratorio con algunos casos del TJDFT.

Palabras clave: Judicial, Eficiencia, Tasa de Recorribidad, Tasa de Reversibilidad.

\section{SUMÁRIO}

INTRODUÇAO; 1 A ESTRUTURA HIERÁRQUICA DO JUDICIÁRIO BRASILEIRO; 2 POR QUE AS PARTES RECORREM?; 3 AS TAXAS DE RECORRIBILIDADE E DE REVERSIBILIDADE COMO INSTRUMENTO DE GESTÃO JUDICIAL; 4 TAXAS DE RECORRIBILIDADE E DE REVERSIBILIDADE NO TJDFT - UM EXPERIMENTO; CONCLUSÃO; REFERÊNCIAS. 


\section{INTRODUÇÃO}

“O que não é medido, não é gerenciado" é a frase atribuída a Robert Kaplan e David Norton, criadores da conhecida metodologia de gestão estratégica chamada de Balanced Scorecard. A ideia é que a gerência de qualquer instituição ou projeto depende de parâmetros e métricas bem estabelecidas. Nesse contexto, o que se propõe no presente trabalho é disponibilizar e estabelecer a metodologia para o cálculo de duas importantes métricas para avaliar o despenho do Poder Judiciário: a Taxa de Recorribilidade e a Taxa de Reversibilidade. A primeira servirá para mensurar a percepção dos jurisdicionados com relação ao acerto das decisões judiciais ou, pelo menos, à probabilidade subjetiva que estes atribuem à possibilidade dessas decisões serem revertidas (corretas ou não). Já a segunda métrica permitirá avaliar a aderência ou a conformidade das referidas decisões judiciais face ao entendimento do órgão revisional.

O conhecimento isolado de cada uma dessas taxas permite que se chegue a algumas conclusões importantes, como se verá mais adiante, porém, a análise bidimensional de ambas constitui uma poderosa ferramenta para que magistrados e tribunais possam monitorar e ajustar suas condutas individuais e coletivas para atuar de maneira eficiente na prestação do serviço público adjudicatório.

A efetiva aferição e utilização das Taxas de Recorribilidade e de Reversibilidade, acrescidas de outras variáveis relevantes, podem ser utilizadas no desenvolvimento de uma adequada política judiciária, de avaliação de programas específicos, na gestão de desempenho e na análise da carga de trabalho necessária para a alocação dos escassos recursos disponíveis a cada tribunal. Além da desejável transparência, a maior disponibilidade de informações para os agentes envolvidos (partes e magistrados) tende a trazer maior eficiência e racionalidade ao sistema judicial, características que nunca são demais em qualquer sistema, em especial no setor público.

$\mathrm{Na}$ apresentação do tema, o presente trabalho foi estruturado da seguinte forma: inicialmente, apresentaremos a organização hierarquia básica do Poder Judiciário Brasileiro para, em seguida, discutir brevemente a estrutura de incentivos que leva as partes a litigar e a recorrer de decisões desfavoráveis. Após essa contextualização, apresentaremos o modelo proposto para o cálculo das Taxas de Recorribilidade e de Reversibilidade e, então, aplicaremos o modelo em um experimento de cunho qualitativo em uma amostra de decisões obtidas no Tribunal de Justiça do Distrito Federal e Territórios. Seguem breves conclusões. 


\section{A ESTRUTURA HIERÁRQUICA DO JUDICIÁRIO BRASILEIRO}

O Poder Judiciário brasileiro é composto pelos seguintes órgãos (art. 92/CF), cada qual com uma competência específica:

(i) Supremo Tribunal Federal - STF: dar a última palavra em questões constitucionais (art. 102/CF);

(ii) Conselho Nacional de Justiça - CNJ: controlar administrativa e financeiramente o Poder Judiciário e, inclusive, punir administrativamente magistrados (art. 103$\mathrm{B} / \mathrm{CF})$;

(iii) Superior Tribunal de Justiça- STJ: dar a última palavra em matéria de legislação federal e uniformizar as interpretações dos tribunais inferiores (art. 105/CF);

(iv) Tribunais Regionais Federais (TRF) e Juízes Federais: responsáveis pelo julgamento em $1^{\mathrm{a}}$ e $2^{\mathrm{a}}$ instância de questões federais, i.e., nas quais a União, autarquias ou empresas públicas federais sejam autoras, rés, assistentes ou oponentes, exceto aquelas relativas à falência, acidentes de trabalho e àquelas do âmbito da Justiça Eleitoral e da Justiça do Trabalho (arts. 108 e 109/CF);

(v) Tribunal Superior do Trabalho (TST), Tribunais e Juízes do Trabalho: responsáveis pelo julgamento em $1^{\mathrm{a}}, 2^{\mathrm{a}}$ e $3^{\mathrm{a}}$ instância de questões envolvendo relações de trabalho (art. 111/CF);

(vi) Tribunal Superior Eleitoral (TSE); Tribunais e Juízes Eleitorais: responsáveis pelo julgamento em $1^{\mathrm{a}}, 2^{\mathrm{a}}$ e $3^{\mathrm{a}}$ instância de questões envolvendo questões eleitorais (art. $121 / \mathrm{CF})$;

(vii) Superior Tribunal Militar (STM), Tribunais e Juízes Militares: responsáveis pelo julgamento em $1^{\mathrm{a}}, 2^{\mathrm{a}}$ e $3^{\mathrm{a}}$ instância de crimes militares (art. 124/CF); e

(viii) Tribunais (TJ) e Juízes dos Estados e do Distrito Federal e Territórios: responsáveis pelo julgamento em $1^{\mathrm{a}}$ e $2^{\mathrm{a}}$ instância de questões estaduais (art. $125 / C F)$.

Para uma melhor compreensão, a estrutura organizacional do Judiciário pode ser representada de forma simplificada da seguinte maneira: 
Figura 1: Estrutura Hierárquica do Judiciário

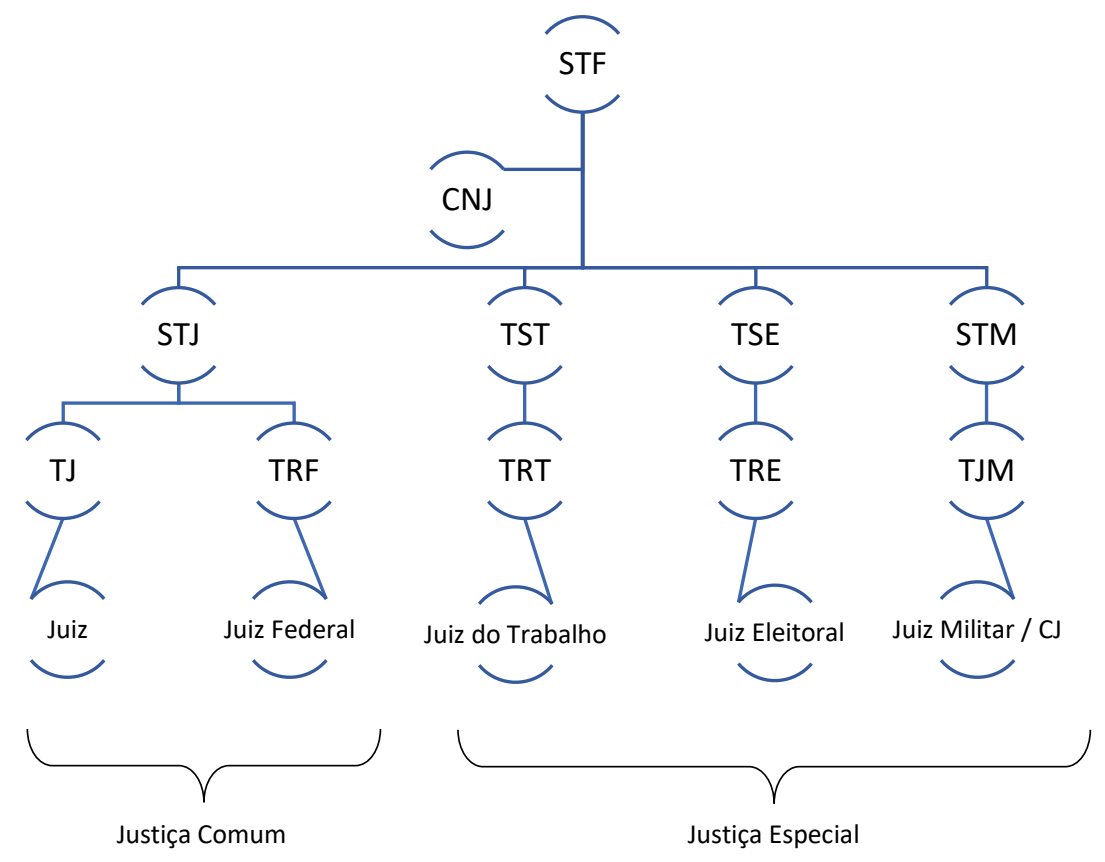

Note-se que, em verdade, a organização judiciária brasileira é muito mais complexa do que é retratado na figura acima. Há uma grande quantidade de exceções para casos específicos, como, por exemplo, o julgamento das infrações penais comuns cometidas pelo Presidente da República, realizado em instância única no STF (art. 102, inc. I, "b”/CF), ou a Justiça Militar que, em Minas Gerais, São Paulo e Rio Grande do Sul, tem tribunal de segunda instância, isto é, um Tribunal de Justiça Militar, cujo papel, nos demais estados, é desempenhado pelo Tribunal de Justiça comum. Não obstante, para as questões debatidas no presente trabalho, esse modelo simplificador é representativo das relações de julgamento e revisão (recurso) e, portanto, satisfatório.

Nessa linha, é interessante considerar o STF como o órgão máximo do Poder Judiciário, pois ele dará a última palavra em questões constitucionais e todas as questões infraconstitucionais devem - em última instância - estar de acordo com a Constituição. Por outro lado, STJ, TST, TSE e STM desempenham papéis semelhantes de garantidores últimos de aplicação da legislação e de uniformização de jurisprudência em suas respectivas competências. Da mesma forma, a lógica e a dinâmica entre magistrados de $1^{\circ}$ grau e magistrados de $2^{\circ}$ grau é similar, se não igual, em cada uma das justiças. Por isso, sem perda de generalidade, a análise a seguir se concentrará apenas na estrutura da justiça comum estadual e sua relação com o STJ e STF.

De forma esquemática, o primeiro contato, a instrução e o julgamento de um caso são realizados por um juiz singular, o qual conduzirá o processo com o auxílio dos advogados das 
ISSN 1981-3694

(DOI): $10.5902 / 1981369431820$

\section{U UDIREITO}

TAXA DE RECORRIBILIDADE, TAXA DE REVERSIBILIDADE E EFICIÊNCIA JUDICIAL

IVO TEIXEIRA GICO JUNIOR HENRIQUE HARUKI ARAKE

partes. Ao final, o juiz decidirá a questão em uma sentença (art. 203/CPC), com ou sem resolução do mérito (arts. 485 e 487/CPC). Dessa decisão cabe recurso da parte que sucumbir, parcial ou integralmente, para o tribunal que, por sua vez, é formado por colegiados, denominados turmas, cujos magistrados integrantes são chamados desembargadores. Portanto, enquanto a decisão de $1^{\mathrm{a}}$ instância é singular, a decisão de $2^{\mathrm{a}}$ instância é, em geral, coletiva. Da decisão do Tribunal de Justiça, que se chama acórdão por ser coletiva, cabe ainda Recurso Extraordinário (“RE”) para o STF (art. 102, II, “a”, da CF), em caso de violação da Constituição, e Recurso Especial (“REsp”) para o STJ (art. 105, III, “a”, da CF), em caso de violação de legislação federal ou interpretação divergente entre Tribunais (art. 105, III, “c”, da CF).

Como se pode ver, supondo-se a unicidade de posicionamento dentro do Tribunal de Justiça, do STJ e do STF (alinhamento horizontal), o sistema parece estruturado para convergir à uniformização de regras jurídicas (alinhamento vertical), já que todas as decisões das etapas anteriores são passíveis de revisão pelo STJ e/ou pelo STF. Todavia, é importante indagar se a simples possibilidade de decisões contrárias serem revertidas nas instâncias superiores é suficiente para dissuadir posicionamentos divergentes, uniformizar a jurisprudência nas instâncias inferiores e criar segurança jurídica (cfr. GICO JR., 2014). Por ora, foquemos a estrutura organizacional e nos mecanismos processuais que nos informam a dinâmica da litigância.

Dentro dessa estrutura organizacional, podemos resumir simplificadamente a estrutura recursal. Encerrada a instrução processual, o juiz profere a sentença. A parte que teve o seu interesse desatendido, parcial ou integralmente, pode questionar essa sentença por meio de recurso ao tribunal superior. Esse recurso, na Justiça comum, chama-se apelação, a qual será apreciada pelo tribunal. A decisão final do tribunal em relação à apelação se chama acórdão, que, por sua vez, só pode ser atacado em duas hipóteses: (a) na presença de uma violação à lei federal ou de interpretações discrepantes dentre tribunais, quando caberá REsp para o STJ; ou (b) na presença de uma violação a dispositivo constitucional, quando caberá RE para o STF. Por fim, do acórdão do STJ, que normalmente também julga por meio de turmas compostas por ministros, ainda cabe um RE para o STF, caso a decisão do STJ tenha violado a constituição.

Na sistemática processual atual, RE e REsp podem e devem ser protocolados no tribunal $a$ quo simultaneamente, se estiverem presentes as hipóteses permissivas de ambos (questão de legalidade e de constitucionalidade). Portanto, mesmo que uma questão possa ser resolvida do ponto de vista legal ou constitucional de forma independente, a estrutura processual gera incentivos para que o agente interponha os dois recursos simultaneamente, sob pena de 
preclusão1. Resumindo o exposto acima, podemos organizar a estrutura recursal da seguinte forma:

Figura 2: Estrutura Recursal Simplificada

Tribunal ( $3^{\mathrm{a}}$ instância)

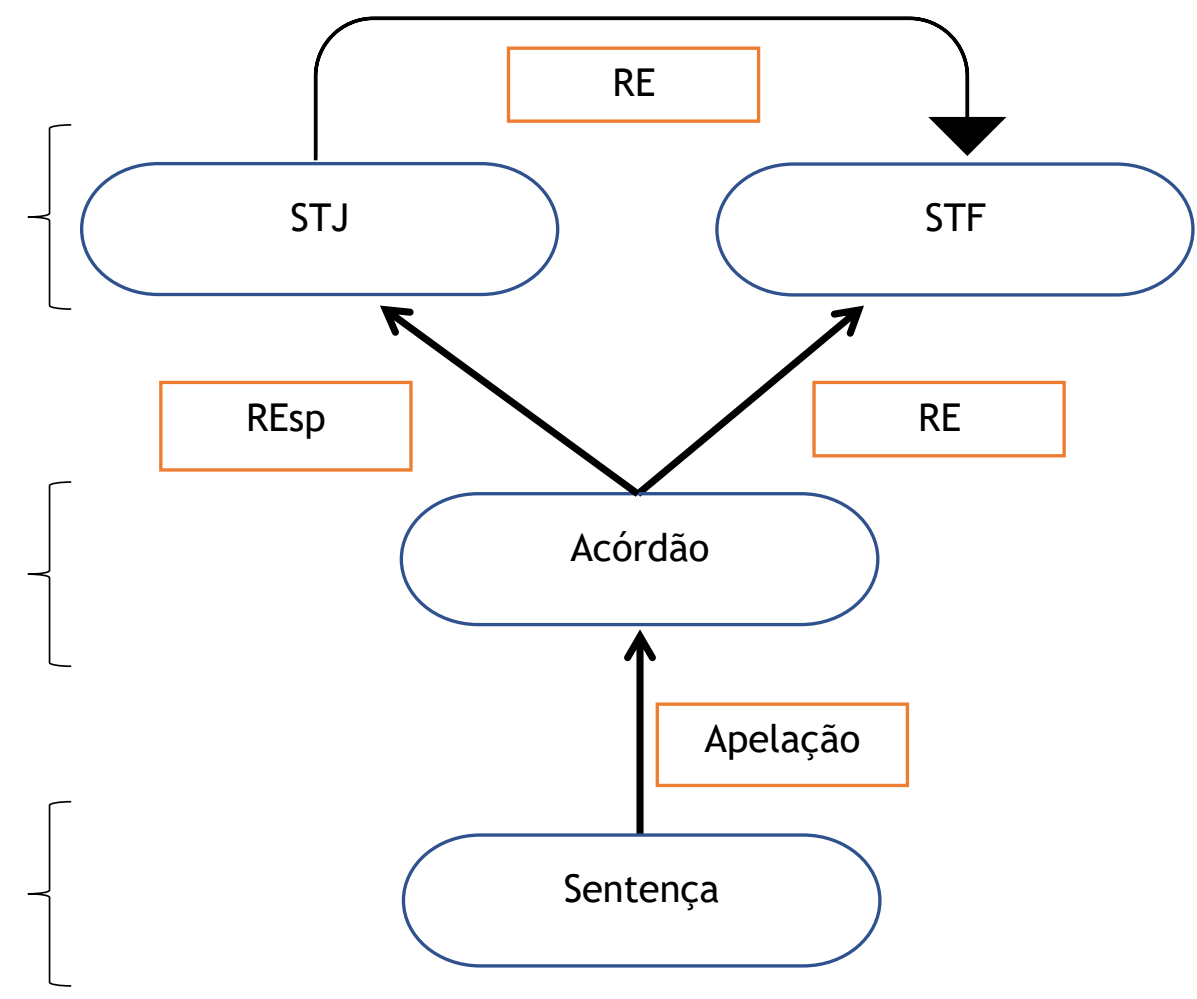

Agora que a estrutura organizacional e processual na qual se inserem os magistrados brasileiros está mais clara, ainda que de forma simplificada, devemos perguntar qual é a estrutura de incentivos das partes em interpor uma apelação após uma decisão judicial. A seção seguinte explora essa questão.

\section{POR QUE AS PARTES RECORREM?}

Na tradição juseconômica (e.g. LANDES, 1971; GOULD, 1973; POSNER, 1973; LANDES e POSNER, 1976), a premissa inicial é de que a parte que escolhe litigar realiza uma escolha racional.

${ }^{1}$ Para uma maior discussão sobre a estrutura de incentivos de recursos, vide Arake e Gico Jr. (2015). 
ISSN 1981-3694

(DOI): $10.5902 / 1981369431820$

\section{UDIREITO}

TAXA DE RECORRIBILIDADE, TAXA DE REVERSIBILIDADE E EFICIÊNCIA JUDICIAL

IVO TEIXEIRA GICO JUNIOR HENRIQUE HARUKI ARAKE

Uma ação judicial, para a parte litigante, seja ela autora ou ré, é uma decisão racional na qual são ponderados os custos e os benefícios esperados de se usar esse mecanismo social de resolução de conflito. Com ou sem a participação de advogados (como nos juizados especiais ou nas instâncias ordinárias da Justiça do Trabalho), ainda que intuitivamente, as partes tentam estimar a probabilidade de sucesso, bem como os custos associados à realização de um acordo ou de continuar litigando. Ambas as partes sabem que incorrem em uma margem de erro nessa estimativa.

O resultado dessas estimativas individuais determinará, em larga medida, a disponibilidade de as partes realizarem acordos. Como em qualquer troca voluntária, há chance de acordo quando a proposta máxima de acordo aceita pelo réu exceder a proposta mínima aceitável pelo autor. 0 autor realizará um acordo quando o retorno esperado da ação for igual ou próximo do valor oferecido em proposta de acordo pelo réu, pressupondo-se a neutralidade ao risco. Já o réu realizará o acordo quando o valor esperado da ação for maior ou próximo ao valor que o autor está disposto a aceitar, também se afastando complicações relacionadas à aversão a risco. Assume-se que o custo privado conjunto de litigar é superior ao custo privado conjunto de realizar um acordo. Em um cenário como esse, o acordo não ocorrerá apenas quando as estimativas das partes não coincidirem minimamente e, por isso, não houver um excedente cooperativo a ser dividido. Em outras palavras, a lógica de um acordo é semelhante à lógica de uma troca voluntária (contrato): só ocorrerá se houver um excedente cooperativo a ser distribuído.

Nada obstante, caso uma conciliação seja infrutífera, a primeira decisão em um litígio é tomada pelo autor (“A”), que escolherá se ajuizará ou não uma ação. Caso opte por ajuizá-la, o autor deverá deduzir integralmente seu pedido acompanhado dos documentos existentes e da indicação das provas que pretende produzir. Essa petição inicial poderá ser contestada ou não pelo réu ("R"), que, se contestar, também deverá juntar as provas documentais existentes, apresentar seus argumentos e indicar as demais provas que pretende produzir.

A terá, então, duas opções: i) continuar com o processo (apresentando ou não sua réplica) ou ii) desistir do processo. Caso A desista, então, R terá duas opções: i) aceitar o pedido de desistência ou ii) rejeitá-lo² e aguardar a sentença. Alternativamente, R poderá oferecer uma proposta de acordo para extinguir o processo prematuramente. Nesse caso A terá, então, duas

\footnotetext{
${ }^{2}$ Como foi o Réu quem apresentou a contestação, a desistência da ação está condicionada à sua concordância, nos

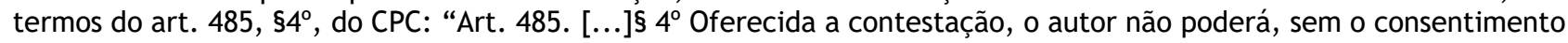
do réu, desistir da ação."
} 
opções: i) aceitar o acordo ou ii) rejeitá-lo e aguardar o processo ser sentenciado. Todas essas decisões estão ilustradas na árvore decisional representada na figura abaixo³:

Figura 3: Estrutura Decisional em uma Ação no $1^{\circ} \mathrm{Grau}$

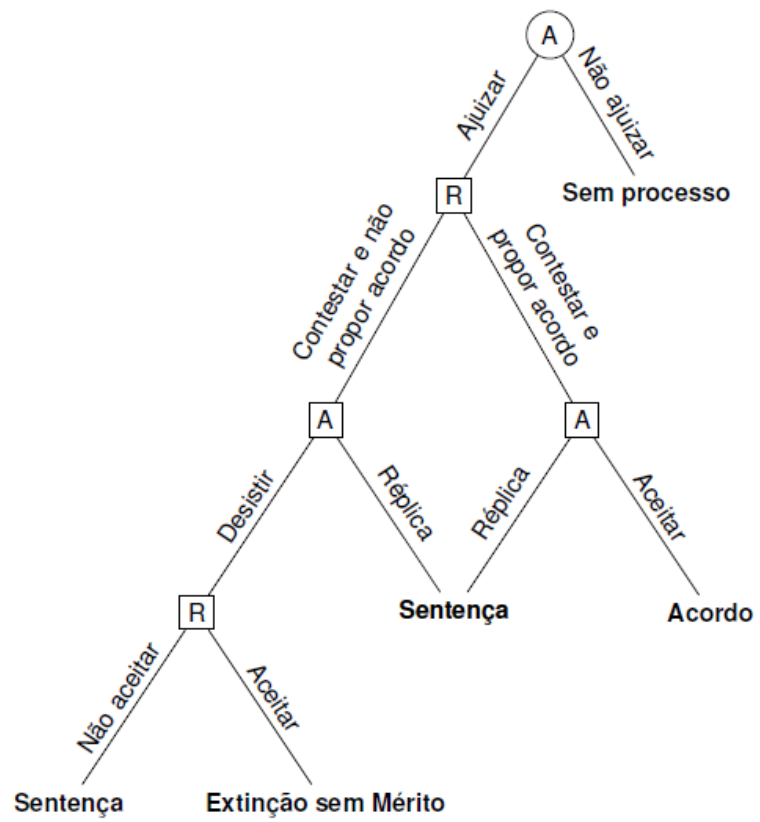

Esse processo de conhecimento é extenso e permite às partes apresentar todos os seus argumentos fáticos e jurídicos perante um juiz, supostamente neutro e imparcial, obtendo-se, assim, uma sentença judicial. Nesse cenário, é importante se perguntar por que as partes recorreriam dessa decisão?

Sabemos que a sentença é o ato por meio do qual o Juiz acolhe ou rejeita, no todo ou em parte, o pedido formulado pelo Autor (arts. 203, \$1 jurisdicional. Nada obstante, no nosso sistema, a regra é que - em geral - todo demandante tem o direito a uma revisão da decisão judicial recebida no que lhe for desfavorável ${ }^{4}$. Dito de outra forma, a parte eventualmente sucumbente pode requerer uma "segunda opinião" de um órgão do

\footnotetext{
${ }_{3}^{3}$ Para fins do presente artigo colocamos o primeiro nódulo de decisão do Réu como contendo uma contestação, para reforçar o valor do acordo, no entanto, o Réu pode optar por sequer contestar e deixar o caso ser julgado.

${ }^{4}$ Há uma grande quantidade de exceções para casos específicos, como, por exemplo, o julgamento das infrações penais comuns cometidas pelo Presidente da República, que é realizado em instância única direto no STF (art. 102, inc. I, "b"/CF), ou a Justiça Militar que, em Minas Gerais, São Paulo e Rio Grande do Sul, tem tribunal segunda instância, isto é, um Tribunal de Justiça Militar e nos demais estados esse papel é desempenhado pelo Tribunal de Justiça comum. Não obstante, para as questões a serem debatidas no presente artigo, esse modelo simplificador é representativo das relações de julgamento e revisão (recurso) e, portanto, é satisfatório.
} 
ISSN 1981-3694

(DOI): $10.5902 / 1981369431820$

\section{UDIREITO}

TAXA DE RECORRIBILIDADE, TAXA DE REVERSIBILIDADE E EFICIÊNCIA JUDICIAL

IVO TEIXEIRA GICO JUNIOR HENRIQUE HARUKI ARAKE

Judiciário de hierarquia superior (art. 996 do $C P C^{5}$ ). 0 acórdão do tribunal, por sua vez, pode ser revisto por um colegiado de juízes (Ministros) no STJ (matéria infraconstitucional) ou no STF (matéria constitucional).

Aberta a fase recursal, a parte sucumbente, seja ela o Autor ou o Réu (ou ambos, em caso de sucumbência recíproca), devem, então, adotar uma de duas opções: i) recorrer da decisão desfavorável ou ii) não recorrer e deixar a decisão transitar em julgado. Caso recorra, a parte adversa, por sua vez, possui também duas opções ${ }^{6}:$ i) apresentar suas contrarrazões ao recurso interposto, isto é, apresentar sua defesa contra os argumentos do recorrente, ou ii) não apresentar suas contrarrazões (inocorrendo aqui os efeitos da revelia) ${ }^{7}$. Independentemente da decisão da parte recorrida, o recorrente tem, ainda, a opção de desistir do recurso interposto. Desistência esta que aqui não está condicionada à concordância da parte recorrida (art. 998/CPC). A figura abaixo ilustra a dinâmica dessa etapa processual:

Figura 4: Estrutura Recursal Em Ação

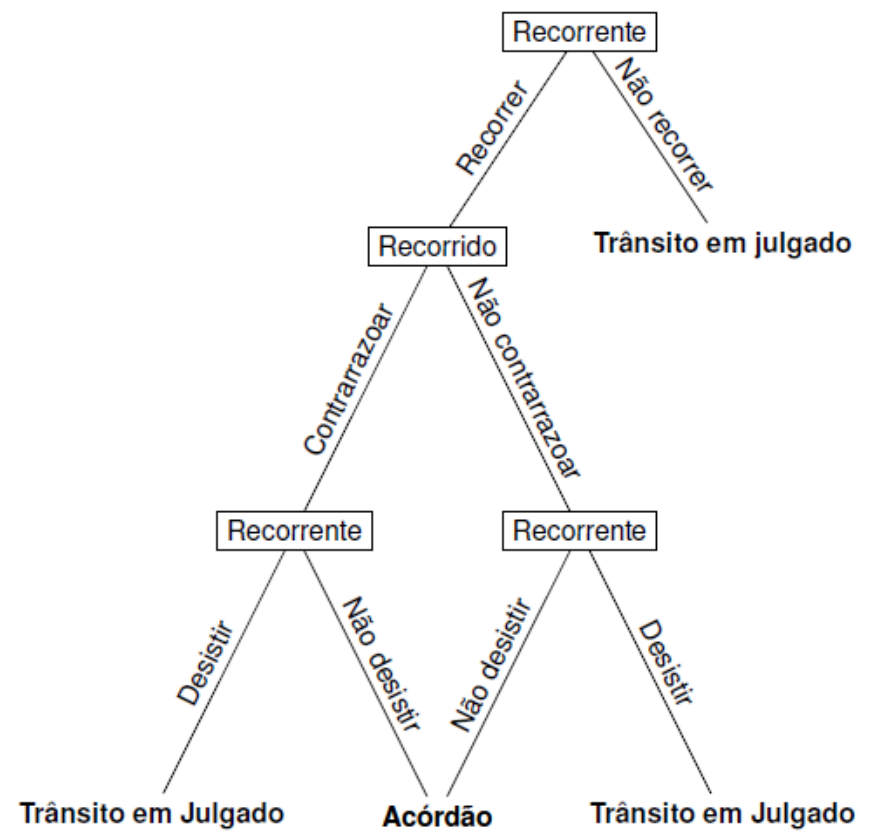

\footnotetext{
${ }^{5} \mathrm{O}$ recurso pode ser interposto pela parte vencida, ou seja, pelo sucumbente, pelo terceiro prejudicado e pelo Ministério Público.

${ }^{6}$ Para alguns recursos, existe a possibilidade de se recorrer adesivamente (art. $997, \$ 1^{\circ}$, do CPC), ato que pode ser interpretado como uma "segunda chance" para a perda do prazo de recorrer ou um "contra-ataque". Para uma discussão mais aprofundada, veja Arake e Gico (2015).

${ }^{7}$ No entanto, é importante verificar se a simples possibilidade de decisões contrárias serem revertidas nas instâncias superiores é suficiente para uniformizar a jurisprudência nas instâncias inferiores e, assim criar segurança jurídica (cfr. GICO JR., 2014).
} 
O termo "recurso" aqui é utilizado para denominar todos os meios disponíveis às partes para provocar o reexame de determinada decisão judicial dentro do mesmo processo em que esta foi proferida ${ }^{8}$. Sucede que, para que uma parte esteja autorizada a recorrer de uma decisão judicial, é imprescindível a existência de interesse recursal oriundo da sucumbência, parcial ou total, na ação (art. 996/CPC). Exige-se, portanto, que a parte em questão não tenha algum pleito atendido pela decisão que pretende reformar por meio do recurso cabível, disciplinados nos arts. 994 e seguintes do CPC.

Nesse sentido, porque é que um caso vai parar no Judiciário, sendo que as partes poderiam realizar um acordo? ${ }^{9}$ As partes não litigam apenas porque tiveram um direito violado, mas também por causa dos baixos custos de acesso e risco e, também, das perspectivas de ganho ${ }^{10}$. Entretanto, o litígio é o resultado da incapacidade de as partes alcançarem um acordo, e essa incapacidade decorre de estimativas diversas de autor e de réu das chances de sucesso de cada um, e, assim, de uma incapacidade em se concordar com o retorno esperado do litígio.

O Brasil, já há algum tempo, vem subsidiando a litigância ao criar os juizados especiais nos quais não é necessário um advogado ${ }^{11}$ e não existem custas processuais ${ }^{12}$, reduzindo-se consideravelmente os custos de um processo. Criou, ainda, a Defensoria Pública e a assistência judiciária gratuita, possibilitando ao sucumbente não ter que pagar custas processuais mesmo na justiça comum. No entanto, tudo isso tem custos que são repassados ao contribuinte, ou seja, toda a sociedade é quem paga os custos subsidiados de cada processo. Trata-se, portanto, de uma opção política de transferir renda do contribuinte para o litigante.

No âmbito de um litígio a revisão de uma decisão judicial por um colegiado não é obrigatória $^{13}$, sendo lícito à parte sucumbente conformar-se com o resultado desfavorável e com as eventuais consequências dali decorrentes. É possível, portanto, que a parte sucumbente prefira que o processo se encerre imediatamente, do que recorrer com relação ao tópico no qual a decisão Ihe foi desfavorável. É possível, ainda, que a parte recorrente prefira desistir do recurso interposto

\footnotetext{
${ }^{8}$ A ação rescisória, portanto, não é considerada um recurso, mas um meio autônomo de reforma de decisão.

${ }^{9}$ Aqui não se trata de preferência, não se faz julgamentos de valor em relação as escolhas, nem se tenta entender porque cada pessoa gosta de uma coisa ou outra, ou porque recorre ou não. Nesse sentido, a teoria econômica é uma teoria sobre os meios empregados pelas pessoas para alcançarem seus fins (comportamentos) e não sobre os fins que elas buscam (motivação).

10 Para aprofundamento da discussão sobre custos de litigância e a estrutura de incentivos das partes, conferir Arake e Gico Jr. (2014).

${ }^{11}$ Exceto para causas de valor entre 20 e 40 salários mínimos ou para interpor e contrarrazoar recurso inominado.

12 Exceto em caso de interposição de recurso inominado.

13 Não estamos tratando das hipóteses de remessa obrigatória, disciplinadas no art. 496 do CPC, pois não são recursos, mas prerrogativa do Estado de ter sentenças contra si analisadas em duas instâncias.
} 
antes de seu julgamento, momento em que a sentença transitará em julgado. Essa decisão não está condicionada à aceitação da parte recorrida (art. 998 e 999 do CPC).

Fato é que a decisão de recorrer será uma decisão racional, tomada pela parte interessada ou pelo seu advogado ${ }^{14}$, à luz das informações disponíveis sobre custos e benefícios. Assim sendo, é esperado que a parte sucumbente recorra apenas se acreditar que os benefícios esperados do recurso, caso seja provido, superem os custos de recorrer e o prejuízo decorrente caso seja desprovido. A Análise Econômica do Direito nos permite modelar essa decisão (cfr. ARAKE, 2012). Antes, porém, é importante discernir o prejuízo adicional decorrente do indeferimento do recurso do custo de recorrer. 0 primeiro são as custas processuais do recurso (preparo e porte de remessa) que serão devolvidas caso o recurso seja provido, o segundo as despesas de recorrer (demora no julgamento do recurso, honorários adicionais para recorrer, etc.). Por fim, cumpre destacar que, na sistemática processual brasileira, via de regra, é vedado que o julgamento do recurso piore a situação do recorrente (reformatio in pejus) ${ }^{15}$. Desse modo, afora as custas processuais e as despesas do recurso, inexiste prejuízo adicional em se recorrer ${ }^{16}$.

Dito isso, é fácil perceber que no exercício da decisão de recorrer ou não de uma decisão judicial, seria interessante para a parte interessada ter o conhecimento da probabilidade de sucesso de seu pleito. Quanto menor a probabilidade de êxito, maior deve ser o ganho almejado para que a decisão de recorrer compense. Do contrário, não recorrerá. Já quanto maior a probabilidade de êxito, menor pode ser o ganho almejado, pois o retorno esperado continuará a ser positivo. De um jeito ou de outro, a consciência da Taxa de Reversibilidade é informação útil para a parte no exercício da prerrogativa de recorrer ou não.

Por outro lado, do ponto de vista do julgador, seria interessante saber não apenas a Taxa de Recorribilidade de suas decisões, isto é, quantas de suas decisões são impugnadas, mas também a Taxa de Reversibilidade, isto é, quantas vezes o tribunal entendeu que suas decisões continham erro. Partindo-se do pressuposto que o Judiciário é uma organização única e que todos os

\footnotetext{
${ }^{14}$ Em várias circunstâncias pode haver um desalinhamento de incentivos entre parte (principal) e o advogado (agente), hipótese na qual o advogado pode tomar uma decisão contrária aos interesses da parte. No entanto, esse assunto foge ao escopo do presente artigo, razão pela qual assumimos que os interesses estão alinhados aqui.

${ }^{15} \mathrm{~A}$ regra é a proibição da reformatio in pejus, no entanto, existe algumas exceções, como na hipótese de no julgamento de apelação contra sentença parcialmente procedente, o tribunal de ofício reconhecer matéria que leve à extinção do processo em relação ao pedido acolhido em primeira instância (e.g. prescrição, ilegitimidade). Os autores agradecem ao avaliador anônimo que apontou essa possibilidade.

${ }^{16}$ Para fins de simplicidade, optamos por não considerar a morosidade para julgamento do recurso como custo neste modelo. Porém, em cenários em que o tempo seja um fator relevante para a tomada de decisão, essa decisão deve ser revista, cfr. Gico Jr. (2014).
} 
magistrados, de $1^{\mathrm{a}}$ e de $2^{\mathrm{a}}$ instancias possuem o mesmo objetivo ${ }^{17}$, qual seja, aplicar corretamente o direito, o acesso à Taxa de Reversibilidade poderia permitir ao juiz ajustar sua conduta em decisões futuras. É o que exploramos a seguir.

\section{AS TAXAS DE RECORRIBILIDADE E DE REVERSIBILIDADE COMO INSTRUMENTO DE GESTÃO JUDICIAL}

Partindo do pressuposto que estamos lidando com tribunais que reformarão uma sentença apenas em casos de erro, aqui considerado como o desvio da jurisprudência do tribunal (direito) ou apreciação equivocada das provas (fatos), podemos postular que o sistema recursal ideal é aquele em que os juízes erram pouco e que as custas de recorrer sejam adequadas a incentivar que as partes recorram apenas em casos de erro e não para financiar e subsidiar suas próprias atividades às custas da mora do Judiciário ${ }^{18}$. Postas essas considerações, vamos apresentar nosso modelo para mensuração da Taxa de Recorribilidade.

A Taxa de Recorribilidade é a razão entre a quantidade de recursos interpostos contra decisões judiciais pelo total de decisões proferidas por uma determinada instância ou órgão julgador. Com ela pretendemos descobrir a relação (proporção) entre as sentenças proferidas que são apeladas e as não apeladas ${ }^{19}$. Para tanto, devemos comparar, dentro de um universo de processos já sentenciados, quantos foram apelados e quantos transitaram em julgado sem apelação. Assim, denotando o universo de processos por $U_{\text {processos }}$ e a quantidade de apelações por $Q_{\text {apelações }}$, temos que a Taxa de Recorribilidade $T_{\text {Rec }}$ será dada pela razão:

$$
T_{\text {rec }}=\frac{Q_{\text {apelações }}}{U_{\text {processos }}}
$$

\footnotetext{
17 Obviamente este pressuposto não necessariamente é verdadeiro. Para uma discussão do Judiciário como um time de objetivos alinhados utilizando a Teoria dos Times, cfr. Gico Jr. (2013). Para uma discussão do Judiciário como um conjunto de agentes com interesses diversos utilizando a Teoria Agente-Principal, cfr. Gico Jr. (2015). Não obstante, em ambos os casos o conhecimento da Taxa de Recorribilidade e de Reversibilidade são úteis e, portanto, deveriam ser produzidas e publicadas.

18 Para maior aprofundamento nessa discussão, cfr. Plutarco (2012).

${ }^{19}$ Fazemos referência aqui à apelação para fins de simplificação, mas a Taxa de Recorribilidade deveria incluir todo e qualquer tipo de ataque à decisão judicial, incluindo agravos e embargos. Quanto mais inclusiva e discriminada, mais informações úteis a taxa revelará.
} 
ISSN 1981-3694

(DOI): $10.5902 / 1981369431820$

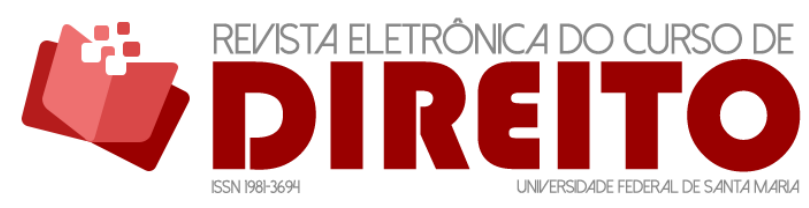

TAXA DE RECORRIBILIDADE, TAXA DE REVERSIBILIDADE E EFICIÊNCIA JUDICIAL

IVO TEIXEIRA GICO JUNIOR HENRIQUE HARUKI ARAKE

O levantamento dessa taxa para cada vara e para cada juiz individualmente considerado revelaria importantes informações para o próprio julgador, para o tribunal a que pertença e para os usuários do serviço público adjudicatório (parte). É importante que a Taxa de Recorribilidade seja construída por vara e por juiz, pois devemos lembrar que tanto os juízes mudam de vara, como há rodízio de julgadores entre titulares e substitutos. A individualização da Taxa de Reversibilidade permitiria a indicação do desempenho de cada vara e de cada julgador, o que, por sua vez, nos permitiria diagnosticar fenômenos e desempenhos próprios de cada um.

Por seu turno, a Taxa de Reversibilidade é a razão entre a quantidade de decisões judiciais revertidas pelo total de decisões recorridas de uma determinada instância ou órgão julgador. Com ela pretendemos descobrir a relação (proporção) entre as sentenças apeladas que são reformadas e as que não são reformadas. Para tanto, devemos comparar, dentro de um universo de sentenças apeladas, quantas foram integral ou parcialmente reformadas e quantas foram mantidas. Assim, denotando o universo de decisões judiciais por $U_{\text {sentenças }}$ e a quantidade de decisões de reforma por $Q_{\text {reformas }}$, temos que a Taxa de Reversibilidade $T_{\text {rev }}$ será dada pela razão:

$$
T_{\text {rev }}=\frac{Q_{\text {reformas }}}{U_{\text {sentenças }}}
$$

O levantamento dessa taxa para cada vara e para cada juiz, bem como para cada turma do tribunal, individualmente considerados, também revelaria importantes informações para o próprio julgador a quo, para o julgador ad quem e, novamente, para os usuários do serviço público adjudicatório (parte). Assim como no caso da Taxa de Recorribilidade, é importante que a Taxa de Reversibilidade seja construída individualmente por vara e por juiz a quo e por revisor e turma ad quem, pois quanto mais detalhados os dados, mais fácil será realizar diagnósticos sobre o que está acontecendo e mais fácil será para todos os agentes envolvidos nessa atividade (partes e julgadores) ajustarem a sua conduta à luz dos resultados obtidos.

Assim, por exemplo, se uma parte está considerando interpor um recurso e sabe de antemão que a Taxa de Reversibilidade de um determinado juiz e/ou de uma determinada vara é baixa, ele naturalmente levará em consideração essa informação na hora de realizar sua escolha. Considerando que as partes são racionais, o resultado esperado é que com o aumento transparência (mais informação) acerca da baixa Taxa de Reversibilidade, a Taxa de Apelabilidade também caia, aumentando o tempo disponível para o tribunal julgar casos mais difíceis ou mais rapidamente. Além disso, quanto mais completa e difundida for a informação, maior a 
ISSN 1981-3694

(DOI): $10.5902 / 1981369431820$

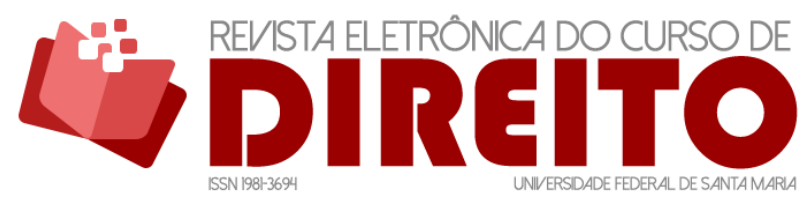

TAXA DE RECORRIBILIDADE, TAXA DE REVERSIBILIDADE E EFICIÊNCIA JUDICIAL

IVO TEIXEIRA GICO JUNIOR HENRIQUE HARUKI ARAKE

probabilidade de que as partes evitem entrar com novas ações para discutir direitos sobre os quais o Judiciário já se manifestou de forma clara. A diminuição da litigância em primeiro grau também deve permitir ao juiz que aloque mais tempo aos casos mais difíceis e, assim, aumente a qualidade de suas decisões e diminua o tempo de adjudicação. Ambos os efeitos tendem a gerar um círculo virtuoso de diminuição de litigância, seguido de um aumento de qualidade das decisões judiciais, o que reforça o círculo virtuoso de litigância ${ }^{20}$.

Por outro lado, se a parte souber que a Taxa de Reversibilidade de um determinado juiz e/ou de uma determinada vara é alta, isso significaria uma maior probabilidade de sucesso do recurso, aumentando-em um primeiro momento-a Taxa de Recorribilidade. No entanto, considerando que os magistrados são racionais, o resultado esperado é que, com o aumento da transparência (mais informação) acerca da alta Taxa de Reversibilidade de suas decisões, o magistrado seja capaz de perceber que há uma divergência constante entre o seu posicionamento e o do tribunal, podendo assim, ajustar a sua conduta. Assim, a redução da assimetria de informação entre tribunal e magistrado permitirá a este que desenvolva com maior segurança e efetividade a sua atividade adjudicatória e-em um segundo momento-, a Taxa de Reversibilidade naturalmente cairá. Mais uma vez, lembrando-se que se trata de uma análise dinâmica, com a queda da Taxa de Reversibilidade, gradualmente, também deve cair a Taxa de Recorribilidade, liberando tempo e recursos de ambas as instâncias para melhor desempenhar suas funções adjudicatórias. Dá-se início a um novo ciclo virtuoso.

Como se pode ver, tanto a Taxa de Recorribilidade quanto a Taxa de Reversibilidade são variáveis dinâmicas e inter-relacionadas, razão pela qual é mais útil e eficiente que se construa e se publique ambas continuamente, pois é esperado que o comportamento dessas taxas varie no tempo, de acordo com o comportamento de todos os agentes envolvidos. Ter acesso a essas informações relevantes, hoje escondidas tanto das partes quanto dos próprios julgadores, é um eficiente instrumento de gestão judicial e deve contribuir significativamente para a celeridade e para o acesso à Justiça.

Para demonstrarmos como, do ponto de vista analítico, é importante que ambas as taxas sejam aferidas e publicadas, suponha agora que, uma vez revelada essa informação oculta (hidden information), se descubra que um determinado órgão judicante possua uma alta Taxa de Recorribilidade agregada. Em uma abordagem inicial, essa taxa pode ser explicada de duas formas: (i) os juízes de primeira instância estão errando muito, na visão do tribunal, ou (ii) os custos de

${ }^{20}$ Sobre o ciclo da litigância, cfr. Gico (2014). 
ISSN 1981-3694

(DOI): $10.5902 / 1981369431820$

\section{LDIREITO}

TAXA DE RECORRIBILIDADE, TAXA DE REVERSIBILIDADE E EFICIÊNCIA JUDICIAL

IVO TEIXEIRA GICO JUNIOR HENRIQUE HARUKI ARAKE

recorrer estão muito baixos para as partes, não tendo muito efeito se o retorno esperado do recurso é baixo. Para resolvermos essa ambiguidade analítica podemos utilizar a agora revelada Taxa de Reversibilidade agregada desse mesmo órgão.

Uma vez aferida a Taxa de Reversibilidade do órgão sob análise, se a taxa for alta, há, também, duas conclusões possíveis: (i) os juízes estão, de fato, errando muito na visão do tribunal; ou (ii) a jurisprudência do tribunal não está clara e a inconstância leva à alta taxa de reversões. Se realizarmos uma simples análise combinatória de todos os resultados possíveis tanto para a Taxa de Recorribilidade quanto para a Taxa de Reversibilidade veremos que, na prática, há quatro cenários possíveis, cada um com suas implicações específicas para a gestão judicial: (alta, alta), (alta, baixa), (baixa, alta) e (baixa, baixa).

Para facilitar a compreensão de cada resultado possível e uma possível comparação entre tribunais e/ou entre varas, podemos conjugar esses resultados em um espaço bidimensional e construir um mapa de desempenho judicial:

Figura 5: Mapa do Desempenho Judicial

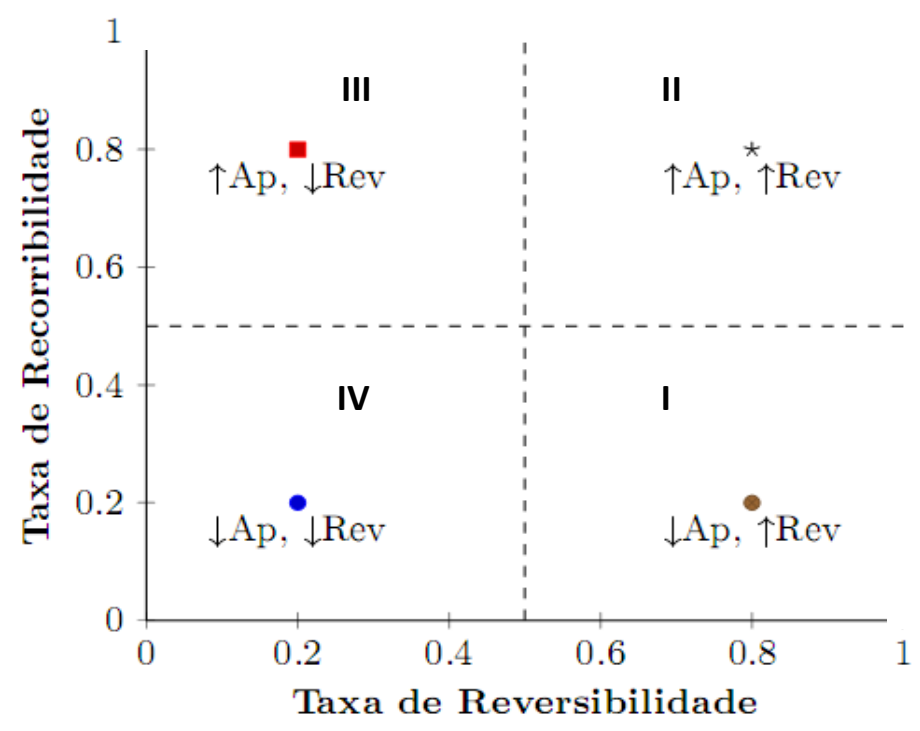

Relembrando o quanto fora afirmado nos parágrafos anteriores, é esperado que a parte sucumbente recorra em duas hipóteses: (i) se acreditar que a probabilidade de reforma da sentença seja suficientemente alta para compensar os custos de recorrer; ou (ii) se os custos de recorrer forem suficientemente baixos para compensar o risco de uma probabilidade de reforma também baixa. 
ISSN 1981-3694

(DOI): $10.5902 / 1981369431820$

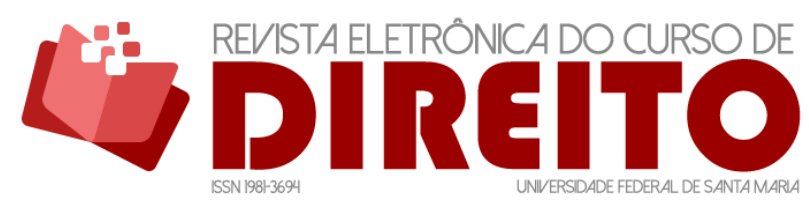

TAXA DE RECORRIBILIDADE, TAXA DE REVERSIBILIDADE E EFICIÊNCIA JUDICIAL

IVO TEIXEIRA GICO JUNIOR HENRIQUE HARUKI ARAKE

Dito isso, os cenários que se coadunam com o item (i) são os quadrantes I e II à direita do gráfico, uma vez que descrevem uma alta Taxa de Reversibilidade e, portanto, uma grande probabilidade de reforma da sentença. Vamos iniciar a discussão por esses quadrantes, portanto. O Quadrante I da Figura 5 (baixa, alta) denota a situação em que há baixa Taxa de Recorribilidade com alta Taxa de Reversibilidade, isso significa que as partes são relativamente capazes de identificar quando houve um erro em uma sentença e, portanto, apelam pouco e preponderantemente nestes casos (baixa Taxa de Recorribilidade). Por outro lado, como os recursos interpostos são preponderantemente de casos com alta probabilidade de reversão, há uma alta Taxa de Reversibilidade. Obviamente, do ponto de vista dinâmico, espera-se que os casos no Quadrante I evoluam gradualmente para o Quadrante II, à medida que os juízes aprendam a posição do tribunal e, portanto, trata-se de um equilíbrio instável ou transitório.

Já o Quadrante II da Figura 5 (alta, alta) denota uma situação indesejável: altas Taxas de Recorribilidade e de Reversibilidade. Logo, há muitas sentenças apeladas e um número substancial dessas apelações é provido. Esse cenário significa que, na visão do tribunal, os juízes estão “errando" muito (são muito revertidos). Nesse caso, a jurisprudência do tribunal pode não estar clara o suficiente e os magistrados não sabem como devem decidir sobre determinada questão ou uma parcela substancial dos juízes simplesmente não seguem a jurisprudência do tribunal, denotando certa rebeldia institucional ${ }^{21}$. Diante de um quadro como esse, o Judiciário poderia realizar uma pesquisa qualitativa para identificar a razão pela qual o comportamento das taxas é (alto, alto). Se o resultado identificado for falta de coerência da jurisprudência, cabe o Pleno do tribunal uniformizar as questões e comunicar de forma clara aos demais magistrados a posição do tribunal (que, obviamente, deve ser seguida pelos desembargadores vencidos), resolvendo o problema. Se o resultado for uma insurgência da primeira instancia, mecanismos de uniformização de jurisprudência devem ser implementados ${ }^{22}$. De um jeito ou de outro, o Judiciário poderá gerir melhor a prestação de seu serviço público adjudicatório.

Note que, do ponto de vista dinâmico, situações no Quadrante II são naturalmente instáveis. Espera-se que tais situações evoluam para o Quadrante I, se os magistrados forem aprendendo a jurisprudência do tribunal e passarem a segui-la, eventualmente seguindo para o Quadrante I, ou a situação evolua para o Quadrante III, no qual estaria identificado que o problema

\footnotetext{
21 Sobre a possiblidade de haver descasamento entre os objetivos dos juízes e dos desembargadores, cfr. Gico (2015).

22 Para uma discussão sobre como criar incentivos para que os magistrados sigam a jurisprudência dos tribunais, cfr. Gico (2014).
} 
ISSN 1981-3694

(DOI): $10.5902 / 1981369431820$

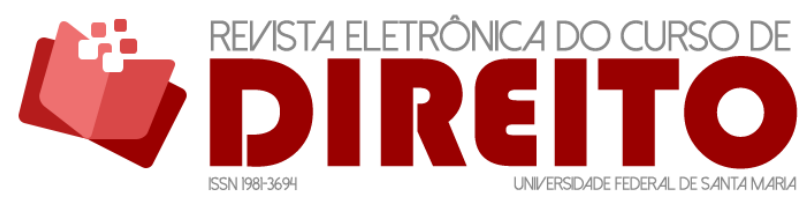

TAXA DE RECORRIBILIDADE, TAXA DE REVERSIBILIDADE E EFICIÊNCIA JUDICIAL

IVO TEIXEIRA GICO JUNIOR HENRIQUE HARUKI ARAKE

é o baixo custo da litigância ou o longo tempo para solução das demandas. De um jeito ou de outro, não se espera que os estados sociais no Quadrante II sejam estáveis.

Por seu turno, o único cenário que se coaduna com o item (ii) (baixo custo de recorrer) é o Quadrante III da Figura 5 (alta, baixa), pois descreve uma alta Taxa de Recorribilidade, porém uma baixa Taxa de Reversibilidade. Desse modo, as partes estão recorrendo mesmo em face de uma pequena probabilidade de êxito. Esse cenário indica, portanto, que, mesmo os juízes errando pouco e o tribunal respeitando as sentenças prolatadas, as partes continuam apelando muito, o que pode indicar a necessidade de revisão dos incentivos para as partes recorrerem. Em outras palavras, seria o caso de se considerar o aumento dos custos de apelar em caso de sucumbência.

Nesse sentido, a alteração no Código de Processo Civil, que possibilitou a fixação de honorários de sucumbência de $10 \%$ na primeira instancia e majorá-lo para $20 \%$ em nova sucumbência na segunda instância, parece ser um mecanismo interessante capaz de reverter este quadro. Outra forma não excludente de diminuir os incentivos ao recurso aventureiro é o aumento das custas processuais em caso de apelação. A eliminação do teto das custas pode ser especialmente interessante, inclusive para reduzir o subsídio público ao litigante. Como se pode ver, o conhecimento das Taxas de Recorribilidade e de Apelabilidade pode ser utilizado para informar a formulação e aplicação de política judiciária.

De qualquer forma, do ponto de vista dinâmico, espera-se que eventual estado social no Quadrante III evolua ou para o Quadrante IV, supondo-se que as partes tenham aprendido que a probabilidade de sucesso em caso de recurso é baixa, ou que o quadro se reverta para o Quadrante II, interpretando-se esse comportamento como tendo o tribunal aprendido que determinada posição precisava de revisão e, por isso, as partes estavam apelando muito. De um jeito ou de outro, o estado social no Quadrante III não é estável.

Por fim, o Quadrante IV da Figura 5 (baixa, baixa) descreve um cenário de baixa Taxa de Recorribilidade e baixa Taxa de Reversibilidade, considerado um cenário socialmente desejável, pois as partes, em regra, se conformam com as sentenças, pois a probabilidade de reforma pelo tribunal é baixa e essa situação é conhecida, o que se confirma pela baixa Taxa de Recorribilidade. Nesse caso, a aderência dos magistrados à orientação jurisprudencial é alta, o que se confirma pela baixa Taxa de Reversibilidade. Em outras palavras, esse cenário indica que os juízes estão, na visão do tribunal, errando pouco e que existem poucas pessoas tentando mudar a jurisprudência consolidada, sem sucesso. É um quadro de maturação e estabilidade judicial, típica de jurisdições consolidadas em que há constância e conhecimento das regras jurídicas em vigor. 
ISSN 1981-3694

(DOI): $10.5902 / 1981369431820$

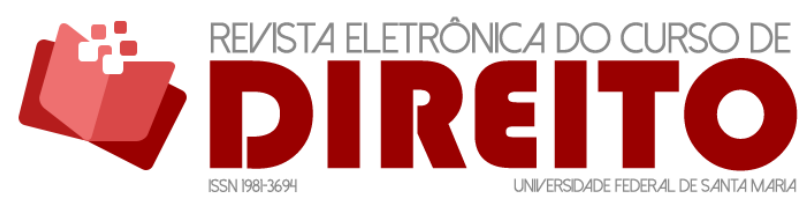

TAXA DE RECORRIBILIDADE, TAXA DE REVERSIBILIDADE E EFICIÊNCIA JUDICIAL

IVO TEIXEIRA GICO JUNIOR HENRIQUE HARUKI ARAKE

Não obstante, considerando-se a quantidade impressionante de casos no Judiciário brasileiro, deve-se tomar particular cuidado com um desempenho judicial que se enquadre no Quadrante IV, pois esse cenário pode indicar não a maturação do sistema judicial brasileiro, mas a presença da nefasta jurisprudência defensiva, em que soterrados pelo excesso de trabalho, os tribunais abandonam por completo qualquer compromisso com a correta aplicação da lei e passam a focar única e exclusivamente na redução quantitativa de casos, na prática, recusando-se a julgálos corretamente. Outra hipótese plausível é o corporativismo judicial, em que para não ferir suscetibilidades de seus colegas, um magistrado se recusa a rever a decisão do outro. Apesar de plausível, a experiência parece indicar que o fenômeno é mais comum entre Desembargadores e Ministros dos Tribunais Superiores (corporativismo horizontal) do que entre instâncias (corporativismo vertical), o que explicaria a dificuldade de os Plenários uniformizarem a jurisprudência dentro do próprio tribunal em face de divergência entre as Turmas que o compõem.

Feitas essas apresentações teóricas, seria interessante demonstrarmos a utilidade das Taxa de Recorribilidade e de Reversibilidade para a gestão judicial em casos concretos. No entanto, os dados necessários para calcular esses índices não estavam disponíveis no momento de elaboração do presente artigo. Não foi possível, assim, calcular as Taxas de forma acurada para um grande número de órgãos. Nada obstante, como o objetivo deste artigo é estabelecer a validade da metodologia, optamos por aplicá-la em um experimento exploratório que será descrito na próxima seção.

\section{Taxas de Recorribilidade e de Reversibilidade no TJDFT - Um} Experimento

Para demonstrar a metodologia proposta, analisamos aleatoriamente dez processos sentenciados entre $1^{\circ}$ de janeiro de 2009 e 31 de dezembro de 2009 de cada uma das vinte Varas Cíveis da Circunscrição Especial Judiciária de Brasília, então existentes ${ }^{23}$, totalizando uma amostra de duzentos processos. Tomamos o cuidado de escolher apenas processos já sentenciados que tenham sido apelados ou que tenham transitado em julgado. A Tabela 1 apresenta a consolidação desses dados, indicando que, se a amostra utilizada for representativa do desempenho do TJDFT, teremos uma Taxa de Recorribilidade média de $46 \%$ nas varas cíveis:

${ }^{23}$ Atualmente, existem vinte e cinco Varas Cíveis nessa Circunscrição. 


\section{Tabela 1 - Resultado Consolidado - Recorribilidade}

\begin{tabular}{|c|c|c|}
\hline Vara Cível & Apelações & Transitados \\
\hline 1 & 8 & 2 \\
\hline 2 & 6 & 4 \\
\hline 3 & 2 & 8 \\
\hline 4 & 6 & 4 \\
\hline 5 & 2 & 8 \\
\hline 6 & 3 & 7 \\
\hline 7 & 6 & 4 \\
\hline 8 & 4 & 6 \\
\hline 9 & 6 & 4 \\
\hline 10 & 6 & 4 \\
\hline 11 & 6 & 4 \\
\hline 12 & 3 & 7 \\
\hline 13 & 5 & 5 \\
\hline 14 & 4 & 6 \\
\hline 15 & 3 & 7 \\
\hline 16 & 4 & 6 \\
\hline 17 & 5 & 5 \\
\hline 18 & 6 & 4 \\
\hline 19 & 2 & 8 \\
\hline 20 & 5 & 5 \\
\hline
\end{tabular}

A seguir, analisamos doze acórdãos de cada uma das seis Turmas do Tribunal de Justiça do Distrito Federal e Territórios - TJDFT. A Tabela 2 apresenta a consolidação desses dados, da mesma forma que foram colhidos. Entretanto, para os fins deste artigo, não faz diferença se a apelação foi acolhida integralmente ou apenas parcialmente, assim sendo, ao somarmos esses resultados, encontramos uma Taxa de Reversibilidade média de 40,28\%: 
Tabela 2 - Resultado Consolidado - Reversibilidade

\begin{tabular}{c|c|c|c}
\hline Turma & Provido & Parcialmente provido & Improvido \\
\hline 1 & 1 & 3 & 8 \\
\hline 2 & 4 & 1 & 7 \\
\hline 3 & 2 & 2 & 8 \\
\hline 4 & 3 & 2 & 7 \\
\hline 5 & 1 & 2 & 9 \\
\hline 6 & 4 & 4 & 4 \\
\hline
\end{tabular}

Considerando-se que os resultados, apesar do tamanho da amostra, sejam representativos do desempenho do TJDFT, teríamos uma Taxa de Recorribilidade média de 46\% e uma Taxa de Reversibilidade média de $40,28 \%$. Esses resultados colocariam o TJDFT quase no centro dos Quadrantes na Figura 5, mas posicionado na região nordeste do Quadrante IV, conforme demonstrado na Figura 6 abaixo, indicando que cerca da metade das sentenças são apeladas e destas, metade são reformadas, sendo o equivalente estatístico de decidir no "cara ou coroa"24:

Figura 6: Desempenho do TJDFT

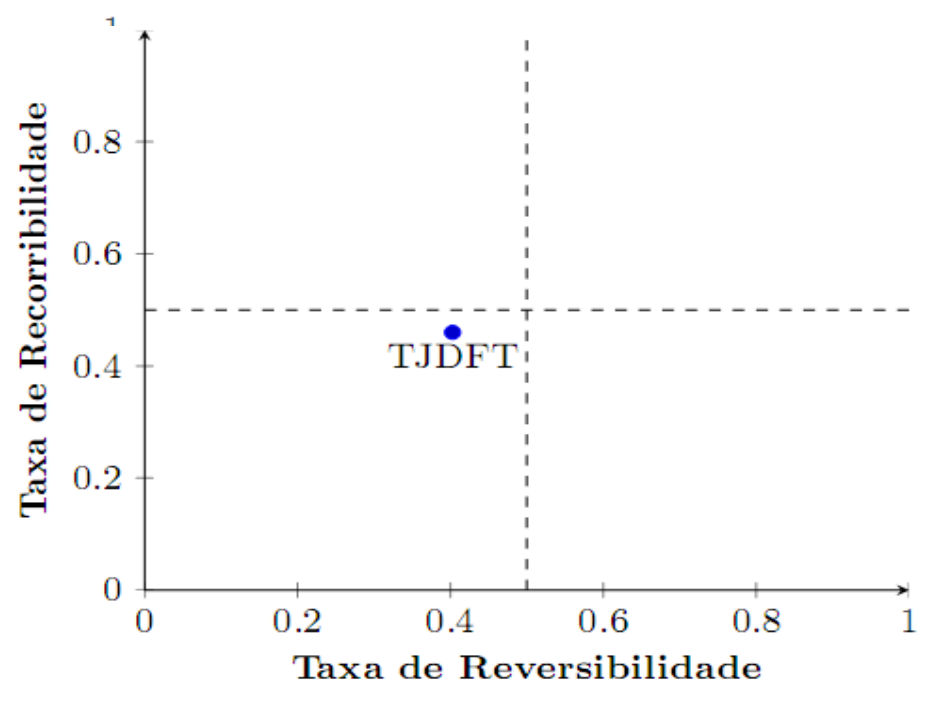

\footnotetext{
${ }^{24}$ Em termos estatísticos, supondo que as decisões judiciais são variáveis aleatórias independentes, isso significaria dizer que o valor esperado (ou média ou esperança matemática) de uma determinada apelação é a soma dos produtos dos valores assumidos pela variável pelas respectivas probabilidades da variável assumir tais valores. Se ganhar ou perder tem $50 \%$ de chances de ocorrer, basta que o direito pedido seja moderadamente valioso para que seja irracional não recorrer.
} 
Nesse sentido, considerando os resultados segundo os quais metade das sentenças são apeladas e, do universo apelado, metade são reformadas, caso haja uma indexação das informações por tema e por tipo de processo, essas informações poderiam ser utilizadas por magistrados em primeira e segunda instância para reajustarem suas condutas e, assim, reduzir tanto a Taxa de Recorribilidade, quanto a Taxa de Reversibilidade, que, obviamente, em um segundo momento, pode ou não voltar a crescer, a depender de onde o equilíbrio se encontre (Quadrante I ou IV).

De um jeito ou de outro, se cada juiz e cada desembargador do TJDFT tivesse acesso a todas essas informações agregadas e analíticas, cada um poderia ter uma melhor compreensão de seu desempenho em relação aos colegas, às demais turmas e dentro do próprio tribunal, diminuindo os custos de comunicação organizacionais e facilitando a cooperação entre magistrados. 0 acesso a informações acerca da taxa de apelabilidade e a taxa de sucesso das apelações interpostas também facilitaria a comunicação entre as várias instâncias ajudando na formação de jurisprudência, e, com isso, trazendo mais segurança jurídica ao sistema processual brasileiro. Vale notar que as taxas exemplificativas indicadas acima são agregadas e, portanto, as mesmas taxas para varas e magistrados específicos podem ser diversas.

\section{CONCLUSÃO}

Conforme demonstrado acima, a aferição e publicação das Taxas de Recorribilidade e de Reversibilidade agregadas e individualizadas de todos os magistrados e tribunais poderia revelar importantes informações tanto para os próprios magistrados, quanto para as partes envolvidas, reduzindo a litigância e gerando mais eficiência na gestão judicial. A depender dos resultados obtidos com a sua implantação, medidas de política judiciária não intuitivas podem ter de ser adotadas para a adequação do nível ótimo de incentivos para as partes recorrerem, bem como para que magistrados em geral produzam ou sigam a orientação jurisprudencial do tribunal a que estão vinculados.

Entendemos que, caso os tribunais passem a aferir e a publicar Taxas de Recorribilidade e de Reversibilidade agregadas e individualizadas de todos os magistrados e tribunais, importantes insights sobre o estado atual do desempenho judicial de cada tribunal serão revelados e medidas de gestão adequadas poderão ser tomadas para incrementar o desempenho do Judiciário em geral. 
ISSN 1981-3694

(DOI): $10.5902 / 1981369431820$

\section{UDIREITO}

TAXA DE RECORRIBILIDADE, TAXA DE REVERSIBILIDADE E EFICIÊNCIA JUDICIAL

IVO TEIXEIRA GICO JUNIOR HENRIQUE HARUKI ARAKE

Além disso, a disponibilização dessas informações aumentaria a transparência do Judiciário na prestação do serviço público adjudicatório e, portanto, o controle social.

Caso a aferição e a utilização das referidas Taxas de Recorribilidade e de Reversibilidade seja um sucesso, talvez, tais informações possam ser utilizadas no futuro, acrescidas de outras variáveis relevantes, no desenvolvimento de uma adequada política judiciária, de avaliação de programas específicos, na gestão de desempenho e na análise da carga de trabalho necessária para a alocação dos escassos recursos disponíveis a cada tribunal. Além da desejável transparência, a maior disponibilidade de informações para os agentes envolvidos (partes e magistrados) tende a trazer maior eficiência e racionalidade ao sistema judicial, características que nunca são demais em nenhum sistema, em especial no setor público.

\section{REFERÊNCIAS}

ARAKE, Henrique Haruki Cavalcante. A Lógica do Processo Civil. Dissertação de Mestrado. ed. Brasília: Universidade Católica de Brasília - UCB, 2012.

ARAKE, Henrique Haruki Cavalcante e GICO JR., Ivo Teixeira. De Graça, até Injeção na Testa: análise juseconômica da gratuidade de Justiça. Economic Analysis of Law Review, 5, 2014. 166178. Disponivel em:

https://portalrevistas.ucb.br/index.php/EALR/article/view/5\%20EALR\%20166 .

ARAKE, Henrique Haruki Cavalcante e GICO JR., Ivo Teixeira. Quando mais é menos: recursos adesivos como desincentivo a recorrer. Economic Analysis of Law Review, 6, 2015. 115-127. Disponivel em: https://portalrevistas.ucb.br/index.php/EALR/article/view/6188.

GICO JR., Ivo Teixeira. Anarquismo Judicial e Teoria dos Times. Economic Analysis of Law Review, Brasília, v. 4, n. 2, p. 269-294, Jul-Dez 2013.

GICO JR., Ivo Teixeira. A Tragédia do Judiciário. Revista de Direito Administrativo, 267, 2014. 163-198. Disponivel em:

http://bibliotecadigital.fgv.br/ojs/index.php/rda/article/view/46462/44453 .

GICO JR., Ivo Teixeira. Anarquismo Judicial e Segurança Jurídica. Revista Brasileira de Políticas Públicas, Brasília, 5, 2015. 479-499.

GICO JR., Ivo Teixeira. Anarquismo Judicial e Teoria dos Times. Economic Analysis of Law Review, Brasília, 4 (2), Jul.-Dez. 2013. 269-294.

GOULD, John P. The Economics of Legal Conflicts. The Journal of Legal Studies, 2 (2), Junho 1973. 279-300. 
LANDES, William. M. An Economic Analysis of the Courts. Journal of Law and Economics, 14 (1), Abril 1971. 61-107.

LANDES, William M.; POSNER, Richard A. Legal Precedent: A Theoretical and Empirical Analysis. NBER Working Paper Series, Agosto 1976. 1-69. Conference on the Economics of Politics and Regulation.

PLUTARCO, Hugo Mendes. A Sonegação e a Litigância Tributária como Forma de Financiamento. Economic Analysis of Law Review, 3, 2012. 122-147. Disponivel em: https://portalrevistas.ucb.br/index.php/EALR/article/view/3\%20EALR\%20122.

POSNER, Richard A. An Economic Approach to Legal Procedure and Judicial Administration. The Journal of Legal Studies, 2 (2), Junho 1973. 399-458.

Recebido em: 25.03.2018 / Revisões requeridas em: 29.11.2018 / Aprovado em: 11.02.2019 / Publicado em: 18.03.2019

\section{COMO FAZER REFERÊNCIA AO ARTIGO (ABNT):}

GICO JUNIOR, Ivo Teixeira; ARAKE, Henrique Haruki. Taxa de recorribilidade, taxa de reversibilidade e eficiência judicial. Revista Eletrônica do Curso de Direito da UFSM, Santa Maria, RS, v. 14, n. 1, e31820, jan./abr. 2019. ISSN 1981-3694. Disponível em: https://periodicos.ufsm.br/revistadireito/article/view/31820 Acesso em: dia mês. ano. doi: http://dx.doi.org/10.5902/1981369431820.

Direitos autorais 2019 Revista Eletrônica do Curso de Direito da UFSM

Editores responsáveis: Rafael Santos de Oliveira e Angela Araujo da Silveira Espindola

Este obra está licenciado com uma Licença Creative Commons Atribuição-NãoComercial-SemDerivações 4.0 Internacional.

\section{SOBRE OS AUTORES}

\section{IVO TEIXEIRA GICO JUNIOR}

É Doutor em Direito pela USP (2006), Doutor em Economia pela UnB (2012), mestre com honra máxima (James Kent Scholar) pela Columbia Law School, Nova York (2001), Especialista em Processo Civil pelo IBEP (2000) e graduado em Direito pela UnB (1999). Atualmente é Professor de Regulação, Concorrência e Contratos no UniCEUB, além de ser membro-fundador e expresidente da Associação Brasileira de Direito \& Economia. Tem experiência na área de Direito, com ênfase em Direito Comercial e Econômico, atuando principalmente nos seguintes temas: contratos, litígios complexos, cartel, práticas anticompetitivas, advocacia superior e setores regulados. Sua principal área de pesquisa é Direito Concorrencial, Direito Regulatório e Contratos.

\section{HENRIOUE HARUKI ARAKE CAVALCANTE}

Sócio de Gico, Hadmann \& Dutra Advogados (compliance, governança corporativa, falências e recuperações judiciais, fraudes corporativas e reestruturação empresarial). Pesquisador do Núcleo de Estudos em Direito e Economia - NEDE/UniCEUB. Professor adjunto no Centro Universitário de Brasília. Associado à Association of Certified Fraud Examiners (ACFE). Graduado em Direito pela Universidade de Brasília ("A Natureza Jurídica dos Contratos Futuros"). Mestre em Análise Econômica do Direito pela Universidade Católica de Brasília - UCB ("A Lógica do Processo: uma análise econômica do direito processual civil brasileiro" ). Doutorando em Direito no Centro Universitário de Brasília - UNICEUB. Produção técnica com ênfase em análise econômica do direito, direito societário, direito falimentar, governança corporativa, compliance e propriedade intelectual. 